\title{
Attention and implicit memory tests: The effects of varying attentional load on conceptual priming
}

\author{
NEIL W. MULLIGAN \\ Illinois State University, Normal, Illinois
}

\begin{abstract}
The role of attention during encoding is important to many current accounts of the implicit/explicit memory distinction. Some accounts suggest that implicit memory tests reflect automatic (non-attentiondemanding) encoding processes, whereas other accounts (such as the transfer-appropriate-processing view) suggest that performance on conceptual implicit tests requires attention during encoding. The present study manipulates attention at encoding over several levels (by varying short-term memory load) and examines the effects on the category-exemplar production task (a conceptual implicit memory test) and its explicit counterpart, category-cued recall. Dividing attention decreased performance on both tests, but in different ways. Mild divisions of attention reduced recall but not conceptual priming. Strong divisions of attention reduced performance on both tests and, in addition, eliminated conceptual priming entirely. These findings resolve apparently conflicting results in the literature and help to clarify the relationship between attention and performance on implicit memory tests.
\end{abstract}

Over the past 15 years, a great deal of research in cognitive psychology and neuropsychology has focused on the distinction between explicit and implicit memory (e.g., Graf \& Masson, 1993; Roediger \& McDermott, 1993; Schacter, 1987). Explicit memory refers to intentional or conscious recollection of prior experiences and is measured by directing subjects to think back about some prior event and report on it, as is done with free-recall, cuedrecall, and recognition-memory tests. Implicit memory, in contrast, refers to changes in behavior that are produced by prior experience and that affect performance on memory tests that do not require any intentional or conscious recollection, such as the identification of perceptually degraded stimuli or the completion of word fragments. Memory for prior events is inferred from increased ease in identifying, generating, or otherwise processing previously experienced information. The enhanced performance on implicit memory tests is called priming (Roediger \& McDermott, 1993).

The principles that govern performance on explicit and implicit memory tests differ in many ways. Particularly striking examples come from neuropsychology and cognitive gerontology. Compared with healthy control subjects, amnesics are profoundly impaired on explicit memory tests but often not on implicit memory tests (see Shimamura, 1986, 1993, for reviews). Likewise, older adults

This research was supported, in part, by a university research grant from Illinois State University. These results were presented at the annual meeting of the Psychonomic Society, Los Angeles, in November 1995. I would like to thank Philip Merikle, Michael Masson, Kathleen McDermott, Tim Curran, Marilyn Hartman, Elliot Hirshman, and Gordon Redding for very useful comments and suggestions. The assistance of Mark Stilling and Kristin Van Schelven is gratefully acknowledged. Address correspondence to N. Mulligan, Department of Psychology, Illinois State University, Campus Box 4620, Normal IL 61790-4620 (e-mail: nwmulli@rs6000.cmp.ilstu.edu). typically have poorer performance than younger adults on explicit tests but not on implicit tests (see Light, 1991, for a review). Experimental manipulations, such as the levels-of-processing and the read/generate manipulation, also produce dissociations on explicit and implicit memory tests (see Roediger \& McDermott, 1993, for a recent review).

One potentially important difference between implicit and explicit tests centers on the controlled/automatic processing distinction. Controlled (or attention-demanding) encoding processes appear to be necessary for later explicit memory (e.g., Fisk \& Schneider, 1984), but automatic (or non-attention-demanding) encoding processes may suffice for later implicit memory (e.g., Eich, 1984). Several studies indicate that very poorly attended stimuli, which may show no retention on explicit memory tests, may nevertheless lead to significant levels of priming on implicit memory tests (Bornstein, Leone, \& Galley, 1987; Eich, 1984; Hawley \& Johnston, 1991; Jelicic, Bonke, Wolters, \& Phaf, 1992; Kunst-Wilson \& Zajonc, 1980; MacKay, 1973; Mandler, Nakamura, \& Van Zandt, 1987; Merikle \& Reingold, 1991; Seamon, Marsh, \& Brody, 1984; cf. Woods, Stadler \& Cowan, 1995). Other studies have demonstrated that division of attention during encoding impairs explicit test performance but may leave the amount of priming completely unaffected (Gabrieli et al., 1995; Isingrini, Vazou, \& Leroy, 1995; Jacoby, Woloshyn, \& Kelley, 1989; Mulligan \& Hartman, 1996; Parkin, Reid, \& Russo, 1990; Parkin \& Russo, 1990; Russo \& Parkin, 1993; Smith \& Oscar-Berman, 1990). Such findings have prompted some researchers to suggest that performance on implicit memory tests largely reflects automatic encoding processes, whereas performance on explicit tests is crucially dependent on encoding processes that require attentional resources (Besson, Fischler, Boaz, \& Raney, 1992; Graf \& Mandler, 1984; Isin- 
grini et al., 1995; Jacoby, Toth, \& Yonelinas, 1993; Jacoby et al., 1989; Jelicic et al., 1992; Parkin et al., 1990; Parkin \& Russo, 1990). ${ }^{1}$

A somewhat more differentiated view on the relationship between attention and implicit tests of memory is offered by the transfer-appropriate processing (TAP) framework, a prominent account of implicit and explicit memory (e.g., Blaxton, 1989, 1992; Roediger \& McDermott, 1993; Roediger, Weldon, \& Challis, 1989). The TAP view proposes that performance on a memory test benefits to the extent that the cognitive processes carried out during encoding are reengaged at test (Morris, Bransford, \& Franks, 1977). Furthermore, the TAP framework distinguishes between two broad classes of cognitive processing: conceptual processing - the analysis of meaning or semantic features - and perceptual processing - the analysis of perceptual or surface-level features (Blaxton, 1989; Roediger \& McDermott, 1993; Roediger et al., 1989). The most commonly used explicit tests rely on conceptual processing (e.g., free and cued recall, recognition), whereas many commonly used implicit tests rely heavily on perceptual processing (e.g., perceptual identification, word-fragment completion). Consequently, many implicit and explicit tests benefit from different types of encoding procedures (Craik, Moscovitch, \& McDowd, 1994; Roediger et al., 1989; Weldon, Roediger, Beitel, \& Johnston, 1995).

According to the TAP framework, it is critical to note that not all implicit tests are perceptual. Some, such as free association and category-exemplar production, encourage the reengagement of conceptual processes (Blaxton, 1992; Roediger \& McDermott, 1993; Roediger et al., 1989). Performance on conceptual implicit memory tests bears interesting similarities with and differences from performance on perceptual implicit memory tests. For instance, both amnesics and older adults have shown normal levels of priming on both types of implicit tests (Blaxton, 1992; Graf, Shimamura, \& Squire, 1985; Light \& Albertson, 1989). In contrast, several other variables (e.g., levels of processing, read/generate, organizational variables, and modality match between study and test) affect perceptual and conceptual priming differently (Roediger \& McDermott, 1993).

Consideration of conceptual priming raises an interesting contrast between the predictions of the TAP view and expectations based on prior research on attention and implicit memory. The studies cited earlier imply that attention plays little or no role during initial learning, when learning is to be measured with implicit tests. Alternatively, the TAP view proposes that, if attention is required for conceptual processing (as is typically assumed: e.g., Craik, 1983; Craik \& Byrd, 1982), then attention during encoding is crucial to subsequent memory as measured by conceptual implicit tests (Mulligan \& Hartman, 1996).

As cited earlier, the role of attention in implicit memory tests has been examined in several divided-attention studies. For perceptual implicit tests, the results are consistent: if the division of attention does not disrupt identification of study stimuli, then later priming is unaf- fected (see Gabrieli et al., 1995, and Mulligan \& Hartman, 1996, for reviews). This implies that attentional resources (beyond those necessary for identification) play little or no role in perceptual implicit memory.

With regard to conceptual implicit tests, the picture is not as clear. Some studies indicate that conceptual priming requires little or no attention during encoding (Isingrini et al., 1995; Koriat \& Feuerstein, 1976), whereas other studies indicate that the conceptual priming is crucially dependent on attention (Gabrieli et al., 1995; Mulligan \& Hartman, 1996).

To begin resolving this inconsistency, I compare two very similar studies that produced conflicting results. Both Isingrini et al. (1995) and Mulligan and Hartman (1996) used the category-exemplar production task to measure conceptual priming. In this task, subjects are first presented with a series of exemplars from different taxonomic categories. Later, subjects are presented with the names of categories and asked to rapidly produce examples. Although the subjects are not informed of this, some of the categories correspond to studied exemplars and some do not. Conceptual priming is computed as the difference between the proportion of the studied exemplars produced and an appropriate baseline measure. In addition to the category-exemplar production test, both Isingrini et al. and Mulligan and Hartman used categorycued recall, an explicit memory test that uses the same retrieval cues.

In both experiments, the study words were presented visually and attention was divided with a concurrent auditory detection task. Isingrini et al. (1995) found that dividing attention significantly reduced performance on the category-cued recall task, but not on the categoryexemplar production task. ${ }^{2}$ In contrast, Mulligan and Hartman (1996) found robust effects of divided attention on both tasks. Furthermore, dividing attention eliminated conceptual priming but not recall. Isingrini et al.'s results support the idea that conceptual priming does not require attentional encoding and, more generally, that conceptual implicit memory tests are less dependent on attention than are comparable explicit tests. The Mulligan and Hartman results indicate just the opposite: conceptual implicit-memory tests require attentional encoding and, in addition, are more dependent on attention than are comparable explicit tests.

Although there are several differences between these two studies which might account for these divergent results (e.g., use of different category norms; different numbers of exemplars per category), the most promising is the strength of the divided-attention manipulation. Both the type of concurrent task and subjects' accuracy on this task differed across the two studies. Subjects in the Isingrini et al. (1995) study monitored a tape recording of a series of consonants and signaled if they detected a B or a G; they correctly identified $67 \%$ of the target consonants. Subjects in the Mulligan and Hartman (1996) study monitored a tape recording of a series of numbers and signaled if they detected a sequence of three odd numbers in a row; they correctly identified $85 \%$ of the target digit 
strings. Although we do not know for certain which of these two tasks requires more attention, it can be argued that Isingrini et al.'s was a weaker manipulation of attention, because subjects had to evaluate only one stimulus at a time; they did not have to maintain any preceding consonants in memory. In contrast, subjects in the Mulligan and Hartman study had to evaluate each stimulus plus maintain information about immediately preceding stimuli. In addition, Mulligan and Hartman kept their subjects focused on the detection task by prompting the subjects if they missed a target sequence, which may also have contributed to the difference in accuracy between the two studies.

If Isingrini et al.'s (1995) was a weaker manipulation of attention, and if attention is necessary for later conceptual priming, we might expect some small (though possibly nonsignificant) effect of this manipulation. In fact, subjects in the divided-attention condition had lower average performance than those in the full-attention condition. If we consider all four of the age groups in Isingrini et al., we see that each age group exhibited a small (but nonsignificant) effect of divided attention. By a sign test, the null hypothesis of no effect of attention yields $p=.0625$ (one-tailed). This suggests that differences in the strength of the attention manipulation may account for the conflicting results.

In the present experiment, attention at encoding was varied by manipulating short-term memory loads. Prior to the presentation of each study word, the subject was presented with an attentional load of 0 (a full-attention condition), 1 , 3 , or 5 digits and letters. The digits and letters were to be maintained in memory until a RECALL signal was presented a few seconds later. This technique allowed a controlled division of attention over several levels within a single experiment (see, e.g., Engle, Conway, Tuholski, \& Shisler, 1995; Logan, 1979). Subsequently, memory for the study words was measured with either the category-exemplar production test or its explicit counterpart, category-cued recall.

This design allows a more extensive exploration of the relationship between attention and implicit and explicit tests of memory, and speaks to a central aspect of the implicit/explicit distinction. Specifically, are implicit memory tests dependent on attention? If so, are explicit or implicit memory tests more sensitive to (or dependent on) manipulations of attention?

\section{METHOD}

\section{Subjects}

Forty-eight undergraduates at Illinois State University participated in exchange for extra credit in psychology courses.

\section{Design and Materials}

The experiment used a $2 \times 4$ design in which memory test (category-exemplar production or category-cued recall) was manipulated between subjects and attentional load $(0,1,3$, or 5$)$ was manipulated within subjects.

The materials were the same as those used in Mulligan and Hartman (1996) and consisted of six common instances from each of 16 categories (a sport, a fruit, a piece of furniture, a bird, a color, a four-footed animal, an article of clothing, a tree, a musical instru- ment, a part of the human body, a vegetable, a dance, an insect, a substance for flavoring food, a fish, a part of a building) in the Battig and Montague (1969) norms. The items chosen did not rank in the 10 most frequent instances, but were produced by at least 10 of the 400 subjects used in the Battig and Montague norms. The average rank of the selected category members was 17.4 .

Two sets of critical items were created by randomly splitting the 16 categories into two groups of 8 , thus creating two master lists of 48 items each. From each master list, four study lists were created by randomly dividing the 8 categories into four groups of 2 and rotating the exemplars from these categories through each of the four attentional load conditions. In each of the resulting eight study lists, all of the exemplars from a given category were in the same attention condition. Finally, the critical items in each list were randomly ordered, subject to the constraint that no two consecutive items were from the same category. Twelve additional items were chosen from nonselected Battig and Montague categories; four were presented before the list, as practice items, and four were placed at the beginning and end of each list as primacy and recency buffers. Each of the additional items came from a different category, and the average rank of these items was similar to that of the critical items. Each study list was presented to equal numbers of subjects.

Study items were preceded by an attentional load. Nonzero loads were constructed by randomly selecting items from a set of digits (1-9) and a set of letters (B, C, D, F, G, H, J, K, L) according to the following rules: (1) digits and letters occupied alternating positions, with a digit in the first position (attentional loads of 1 consisted of a single digit); and (2) no repetition of digits or letters within a load. It was thought that the use of these materials and rules would help to minimize chunking.

In the category-exemplar production test, all 16 category names were used as cues, 8 of which corresponded to studied words ( 2 categories per load condition) and 8 to new words. Production rates of the nonstudied critical items served as the baseline response rate. Across subjects, each category appeared equally often as studied and new. In the category-cued recall task, the cue set consisted of the 8 category names corresponding to the studied items ( 2 categories per load condition)

\section{Procedure}

The subjects were tested individually. The experiment consisted of a study task and a memory test. At the beginning of the experiment, the subjects were informed that they would perform several different tasks, some having to do with memory and some having to do with language abilities and problem-solving.

Each study trial consisted of the following. First, a ready prompt was displayed for $500 \mathrm{msec}$. Then, the digit-letter string comprising the attentional load (or a dash in the 0 -load condition) was presented for $2.5 \mathrm{sec}$. For the non-0-load trials, subjects were instructed to read the digit-letter string aloud and retain it in memory until the RECALL signal was given. For the 0-load trials, subjects were simply instructed to say "blank" in response to the dash. Next, the study word was presented for $3 \mathrm{sec}$. Subjects were instructed to read the word aloud and try to remember it for a later (unspecified) memory test. Finally, either the word RECALL (in the non-0-load conditions) or the word BLANK (in the 0 -load condition) appeared for $2.5 \mathrm{sec}$. The subjects were instructed either to recall the digits and letters (in the non-0-load conditions) or to again say "blank" (in the 0 -load condition).

After the study list, the subjects were given one of the two memory tests. In the category-exemplar production task, the 16 category names were presented, 1 at a time, with instructions to produce as rapidly as possible the first 8 category exemplars that came to mind. Eight exemplars were required to be sure that exemplars other than the most common were produced (Graf et al., 1985; Rappold \& Hashtroudi, 1991). The experimenter recorded the subjects' responses, and no time limit was imposed. When 8 exemplars were produced, the experimenter signaled the subject to proceed to the 
next category by pressing the space bar on the computer's keyboard. No mention was made of the relationship between this task and the studied words. In the category-cued recall test, the subjects were presented with the 8 category names that corresponded to the study list. They were instructed to use the category cues to recall members of the category that had been previously studied. No time limit was imposed, and the number of responses required was not fixed.

\section{RESULTS}

During the study task, the mean proportion of attentional load items recalled was $.97, .98$, and .91 for the $1-$, $3-$, and 5-load conditions, respectively $[F(2,94)=17.34$, $\left.M S_{\mathrm{e}}=0.0039, p<.0005\right]$. Post hoc comparisons using the Fisher-Hayter test ${ }^{3}$ indicate that performance was significantly worse in the 5 -load condition than in either the 1 - or 3 -load conditions. No other differences were significant. In addition, the mean proportion of study words correctly identified was .993 and did not vary as a function of attentional load $(p>.20)$. Thus, subjects were able to identify virtually all study words while simultaneously maintaining the attentional loads.

The results of the memory tests are presented in Figure 1. For the category-exemplar production task, the dependent measure is the amount of priming (the difference between the proportion of studied and nonstudied exemplars produced). For category-cued recall, the dependent measure is the proportion of studied items recalled. As can be seen in the figure, attentional load had a significant impact on performance in both tasks, but the details differ. In the category-exemplar production task, a substantial division of attention is required before performance drops, at which point performance drops to approximately zero. In contrast, performance in the category-cued recall task decreases with the most mild division of attention, but is still substantially above zero even when attention has been strongly divided.

Statistical analyses confirm these impressions. The priming scores from category-exemplar production and proportions correct from category-cued recall were submitted to separate analyses of variance, using attentional load as a within-subjects factor. Both analyses revealed an effect of attentional load [category-exemplar production, $F(3,69)=4.40, M S_{\mathrm{e}}=0.015, p<.007$; categorycued recall, $\left.F(3,69)=11.49, M S_{\mathrm{e}}=0.0071, p<.001\right]$, indicating that increased attentional load at encoding decreased test performance on both memory tests.

For the category-exemplar production test, the FisherHayter test indicated that priming was significantly lower in the 5-load condition than in any of the other conditions and that no other pair of conditions differed significantly. In addition, $t$ tests revealed that priming was significantly greater than zero in the $0-, 1-$, and 3 -load conditions (all $p s<.005$ ) but not in the 5-load condition ( $p>$ .39). For the category-cued recall test, the Fisher-Hayter test indicated that performance was significantly greater in the 0 -load condition than in any other condition, that performance was significantly lower in the 5-load condition than in any other condition, and that performance
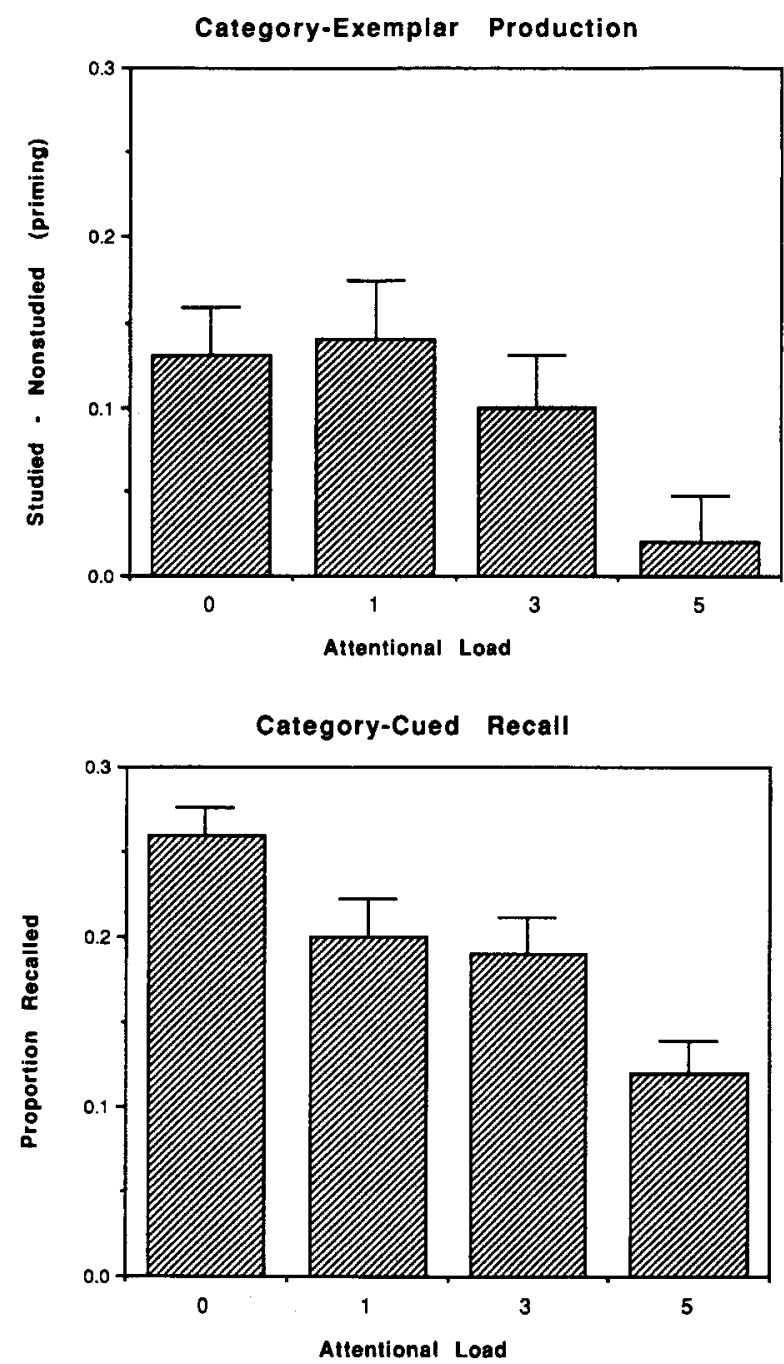

Figure 1. Summary of results: Mean priming $(+S E)$ in the category-exemplar production task and mean proportion of words recalled $(+S E)$ in the category-cued recall test as a function of attentional load at encoding. Note that baseline responding (proportion of nonstudied exemplars produced) for the category-exemplar production task was .13.

did not significantly differ in the 1 - and 3-load conditions. Additionally, $t$ tests indicated that performance in each load condition was significantly above zero (all $p \mathrm{~s}<.001){ }^{4}$

The present results may be viewed as a resolution of the conflicting results of Isingrini et al. (1995) and Mulligan and Hartman (1996). If we consider the 0 -load condition as a full-attention condition and the 3-load condition as a moderately divided attention condition, the results replicate Isingrini et al. Over this range, dividing attention produced a small and nonsignificant decrease on the category-exemplar production task and a larger, significant, decrease on category-cued recall. If we again consider the 0-load condition as a full-attention condition and the 5-load condition as a strongly divided-attention condition, the results replicate Mulligan and Hartman: Di- 
Table 1

Comparison of Mulligan and Hartman (Experiment 1, 1996) Results With the 0- and 5-Load Conditions

Memory Test

\begin{tabular}{lcc} 
& \multicolumn{2}{c}{ Memory Test } \\
\cline { 2 - 3 } & $\begin{array}{c}\text { Category-Exemplar } \\
\text { Production }\end{array}$ & $\begin{array}{c}\text { Category-Cued } \\
\text { Recall }\end{array}$ \\
\hline Mulligan and Hartman & & \\
$\quad$ Full attention & .11 & .23 \\
$\quad$ Divided attention & .02 & .11 \\
Present study & & .26 \\
0 Load & .13 & .12 \\
5 Load & .02 & \\
\hline
\end{tabular}

viding attention produced large, significant decreases in performance on both memory tests. Furthermore, dividing attention not only decreased priming, it eliminated it. As can be seen in Table 1, the current within-subjects manipulation of attention provides a very good quantitative replication of the between-subjects manipulation in Mulligan and Hartman.

The results from the 0 -load condition are also quantitatively quite similar to those reported by Rappold and Hashtroudi (1991) in a study using full-attention encoding. In Rappold and Hashtroudi's Experiment 1 (random condition), mean priming in category-exemplar production was . 10 and mean proportion recalled in category-cued recall was .27. Because this experiment was so similar to the 0-load condition in terms of subjects and materials, the similarity in results lends further credence to the claim that the current within-subjects manipulation of attention produces results consistent with between-subjects manipulations.

Finally, it should be noted that the present results satisfy the retrieval-intentionality criterion (Schacter, Bowers, \& Booker, 1989) in a way that might not have been established if attention had been manipulated as a binary variable. If we consider only the first three load conditions $(0,1$, and 3$)$, we see a dissociation between implicit and explicit versions of a memory test. If the implicit subjects had surreptitiously used intentional retrieval strategies, we would expect decreases in the 1- and 3-load conditions relative to the 0 -load condition, as was seen with the explicit subjects. There is no such decrease across these load conditions. In fact, mean priming in the 1-load condition is (nonsignificantly) higher than in the 0-load condition, a very unlikely outcome if the implicit subjects had engaged in intentional retrieval.

\section{DISCUSSION}

The current results resolve the discrepancies between the Isingrini et al. (1995) and Mulligan and Hartman (1996) studies, and have two primary implications. First, these results provide strong evidence that attention plays a role in performance on implicit memory tests. Consistent with the TAP view, implicit tests that have a strong conceptual component are adversely affected by divided attention at encoding. Second, the relative sensitivity of conceptual implicit and explicit tests to manipulations of attention depends on the strength of the manipulation. With a weak manipulation, the explicit test appears more dependent on attention, in the sense that the manipulation reduces explicit but not implicit test performance. With a stronger manipulation, the implicit test appears more dependent on attentional resources, in the sense that implicit test performance (as measured by priming), but not explicit test performance, is eliminated.

One appealingly simple account of the present results, based on the TAP framework, is that conceptual explicit tests are simply more sensitive to variations in the amount of prior conceptual processing than their implicit counterparts. This account posits that dividing attention decreases the amount of conceptual processing and that explicit tests are more sensitive to the small decreases that accompany weaker divisions of attention. According to this account, conceptual implicit tests are not completely insensitive to variation in the amount of prior conceptual processing, but rather require greater variation before an effect is observed. Finally, strong divisions of attention (e.g., the 5-load condition) presumably lead to small amounts of conceptual processing which go undetected by the relatively insensitive implicit tests. At a general level, this account is consistent with the findings of Hintzman and Hartry (1990), which suggest that old-new study status has substantially less impact (i.e., accounts for much less of the variance) on the overall performance of implicit tests than of explicit tests (though it should be noted that the Hintzman and Hartry study focused on a perceptual implicit test, word-fragment completion).

Although the sensitivity account provides a parsimonious explanation of the present data, it may be incomplete when considered in the context of the amnesic literature, cited earlier. The sensitivity account proposes that conceptual implicit and explicit tests differ along a single dimension, sensitivity to prior conceptual processing. This view would predict that if explicit memory is eliminated, then conceptual implicit memory would be eliminated as well. The amnesic literature contains suggestive, though not definitive, data to the contrary. In a study by Graf et al. (1985), amnesics demonstrated normal priming on category-exemplar production coupled with near-zero explicit memory, as measured by free recall. However, in this study, the overt memory cues were not equated across the conceptual implicit and explicit tests. Blaxton (1992) examined the performance of memory-impaired patients in a study which did equate test cues across implicit (category-exemplar production) and explicit (category-cued recall) tests. Blaxton found that, in some conditions, the memory-impaired subjects exhibited normal conceptual priming coupled with impaired recall. In contrast to Graf et al., Blaxton's memoryimpaired subjects still exhibited a level of recall substantially above zero. However, it should be noted that Blaxton's subjects were not nearly as impaired as Graf et al.'s subjects (as measured by the Wechsler Memory Scale). In sum, Graf et al.'s results appear to be at odds with the sensitivity account, whereas Blaxton's results are very consistent with this account, although neither of these 
studies provides the optimal test of the sensitivity account. A more rigorous test would examine the effects of moderate to profound amnesia on conceptual implicit and explicit memory tests with equivalent overt memory cues.

An alternative to the sensitivity account is based on the common assumption that spatiotemporal context plays a more important role in explicit than in implicit memory tests (e.g., Humphreys, Bain, \& Pike, 1989; Jacoby \& Dallas, 1981; Jacoby \& Hollingshead, 1990; Light \& LaVoie, 1993; Schwartz, Rosse, \& Deutsch, 1993; see, also, Weldon et al., 1995). Under this view, conceptual explicit tests are sensitive to both prior conceptual processing and contextual encoding, whereas conceptual implicit tests are primarily sensitive to prior conceptual processing. This may explain why performance on explicit tests is preserved even after performance on implicit tests is reduced to zero; explicit memory tests are supported by more types of encodings. Although evidence exists that both conceptual processing and contextual processing have attentional requirements (see Cowan, 1995), the relationship between the memorial effects of these processes and attention needs to be worked out in detail.

\section{REFERENCES}

Battig, W. F., \& Montague, W. E. (1969). Category norms for verbal items in 56 categories: A replication and extension of the Connecticut category norms. Journal of Experimental Psychology Monographs, $\mathbf{8 0}$ (3, Pt. 2).

Besson, M., FisChLER, I., BoAZ, T., \& RANEy, G. (1992). Effects of automatic associative activation on explicit and implicit memory tests. Journal of Experimental Psychology: Learning, Memory, \& Cognition, 18, 89-105.

BLAXTON, T. A. (1989). Investigating dissociations among memory measures: Support for a transfer-appropriate processing framework. Journal of Experimental Psychology: Learning, Memory, \& Cognition, 15, 657-668.

BLAXTON, T. A. (1992). Dissociations among memory measures in memory-impaired subjects: Evidence for a processing account of memory. Memory \& Cognition, 20, 549-562.

BoRnsteIN, R. F, LEONE, D. R., \& GALLEY, D. J. (1987). The generalizability of subliminal mere exposure effects: Influences of stimuli perceived without awareness. Journal of Personality \& Social Psychology, 53, 1070-1079.

CoWAN, N. (1995). Attention and memory: An integrated framework New York: Oxford University Press.

CRAIK, F. I. M. (1983). On the transfer of information from temporary to permanent memory. Philosophical Transactions of the Royal Society: Series $B, \mathbf{3 0 2}, 341-359$.

CraIK, F. I. M., \& BYRD, M. (1982). Aging and cognitive deficits: The role of attentional resources. In F. I. M. Craik \& S. E. Trehub (Eds.), Aging and cognitive processes (pp. 191-211). New York: Plenum.

Craik, F. I. M., Moscovitch, M., \& McDowd, J. M. (1994). Contributions of surface and conceptual information to performance on implicit and explicit memory tasks. Journal of Experimental Psychology: Learning, Memory, \& Cognition, 20, 864-875.

Еiсн, E. (1984). Memory for unattended events: Remembering with and without awareness. Memory \& Cognition, 12, 105-111.

Engle, R. W., Conway, A. R. A., Tuholski, S. W., \& Shisler, R. J. (1995). A resource account of inhibition. Psychological Science, 6 , $122-125$.

FisK, A. D., \& SCHNEIDER, W. (1984). Memory as a function of attention, level of processing, and automatization. Journal of Experimental Psychology: Learning, Memory, \& Cognition, 10, 181-197.

Gabrieli, J. D. E., Stone, M. V., Shackleton, K., Thompson-SChill,
S. L., LADD, S. L., VAIDYA, C. J., \& Chari, A. (1995). Attention and implicit memory for words. Manuseript submitted for publication. Graf, P., \& MANDLER, G. (1984). Activation makes words more accessible, but not necessarily more retrievable. Journal of Verbal Learning \& Verbal Behavior, 23, 553-568.

GRAF, P., \& MASSON, M. (1993). Implicit memory. Hillside, NJ: Erlbaum. Graf, P., Shimamura, A., \& SQuire, L. (1985). Priming across modalities and priming across category levels: Extending the domain of preserved functions in amnesia. Journal of Experimental Psychology: Learning, Memory, \& Cognition, 11, 386-396.

HAWLEY, K. J., \& JoHNSTON, W. A. (1991). Long-term perceptual memory for briefly exposed words as a function of awareness and attention. Journal of Experimental Psychology: Human Perception \& Performance, 17, 807-815

HintzMan, D. L., \& HaRTRY, A. L. (1990). Item effects in recognition and fragment completion: Contingency relations vary for different subsets of words. Journal of Experimental Psychology: Learning, Memory, \& Cognition, 16, 955-969.

HumphreYs, M. S., Bain, J. D., \& PiKE, R. (1989). Different ways to cue a coherent memory system: A theory for episodic, semantic, and procedural tasks. Psychological Review, 96, 208-233.

IsINGRINI, M., VAZOU, F., \& Leroy, P. (1995). Dissociation between implicit and explicit memory tests: Effects of age and divided attention on category exemplar generation and cued recall. Memory \& Cognition, 23, 462-467.

JACOBY, L. L. (1991). A process dissociation framework: Separating automatic from intentional uses of memory. Journal of Memory \& Language, 30, 513-541.

JACOBY, L. L., \& DALlas, M. (1981). On the relationship between autobiographical memory and perceptual learning. Journal of Experimental Psychology: General, 110, 306-340.

JACOBY, L. L., \& HollingSHEAD, A. (1990). Toward a generate/recognize model of performance on direct and indirect tests of memory. Journal of Memory \& Language, 29, 433-454.

J ACOBY, L. L., TOTH, J. P., \& Yonelinas, A. P. (1993). Separating conscious and unconscious influences of memory: Measuring recollection. Journal of Experimental Psychology: General, 122, 139-154.

JACOBY, L. L., WOLOSHYN, V., \& KELLEY, C. (1989). Becoming famous without being recognized: Unconscious influences of memory produced by divided attention. Journal of Experimental Psychology: General, 118, 115-125.

Jelicic, M., Bonke, B., Wolters, G., \& Phaf, R. H. (1992). Implicit memory for words presented during anaesthesia. European Journal of Cognitive Psychology, 4, 71-80.

KirK, R.E. (1995). Experimental design (3rd ed.). New York: Brooks/Cole.

Koriat, A., \& Feuerstein, N. (1976). The recovery of incidentally acquired information. Acta Psychologica, 40, 463-474.

KUNST-Wilson, W. R., \& ZaJoNC, R. B. (1980). Affective discrimination of stimuli that cannot be recognized. Science, 207, 557-558.

LIGHT, L. L. (1991). Memory and aging: Four hypotheses in search of data. Annual Review of Psychology, 42, 333-376.

Light, L. L., \& Albertson, S. A. (1989). Direct and indirect tests of memory for category exemplars in young and older adults. Psychology \& Aging, 4, 487-492.

LigHT, L. L., \& LA Vole, D. (1993). Direct and indirect measures of memory in old age. In P. Graf \& M. E. J. Masson (Eds.), Implicit memory: New directions in cognition, development, and neuropsychology (pp. 207-230). Hillsdale, NJ: Erlbaum.

LOGAN, G. D. (1979). On the use of a concurrent memory load to measure attention and automaticity. Journal of Experimental Psychology: Human Perception \& Performance, 5, 189-207.

MacKay, D. G. (1973). Aspects of the theory of comprehension, memory and attention. Quarterly Journal of Experimental Psychology, 25, $22-40$.

Mandler, G., Nakamura, Y., \& Van Zandt, B. J. S. (1987). No specific effects of exposure on stimuli that cannot be recognized. Journal of Experimental Psychology: Learning, Memony, \& Cognition, 13, 646-648

MerikLe, P., \& Reingold, E. (1991). Comparing direct (explicit) and indirect (implicit) measures to study unconscious memory. Journal of $E x$ perimental Psychology: Learning, Memory, \& Cognition, 17, 224-233. 
MoRris, C. D., BRANSFord, J. D., \& FRANKs, J. J. (1977). Levels of processing versus transfer appropriate processing. Journal of Verbal Learning \& Verbal Behavior, 16, 519-533.

Mulligan, N. W., \& Hartman, M. (1996). Divided attention and indirect memory tests. Memory \& Cognition, 24, 453-465.

Parkin, A. J., REID, T. K., \& Russo, R. (1990). On the differential nature of implicit and explicit memory. Memory \& Cognition, 18, 507-514.

PARKIN, A. J., \& Russo, R. (1990). Implicit and explicit memory and the automatic/effortful distinction. European Journal of Cognitive Psychology, 2, 71-80.

RaPPOLD, V. A., \& HaShTROUdI, S. (1991). Does organization improve priming? Journal of Experimental Psychology: Learning, Memory, \& Cognition, 17, 103-114.

ROEDIGER, H. L., III, \& MCDERMOTT, K. B. (1993). Implicit memory in normal human subjects. In F. Boller \& J. Grafman (Eds.), Handbook of neuropsychology (pp. 63-131). Amsterdam: Elsevier.

Roediger, H. L., III, Weldon, M. S., \& Challis, B. H. (1989). Explaining dissociations between implicit and explicit memory: A processing account. In H. L. Roediger III \& F. I. M. Craik (Eds.), Varieties of memory and consciousness: Essays in honour of Endel Tulving (pp. 3-14). Hillsdale, NJ: Erlbaum.

Russo, R., \& PARKIN, A. J. (1993). Age differences in implicit memory: More apparent than real. Memory \& Cognition, 21, 73-80.

SCHACTER, D. L. (1987). Implicit memory: History and current status. Journal of Experimental Psychology: Learning, Memory, \& Cognition, 13, 501-518.

SCHACTER, D. L., Bowers, J., \& BOOKER, J. (1989). Intention, awareness, and implicit memory: The retrieval intentionality criterion. In S. Lewandowsky, J. C. Dunn, \& K. Kirsner (Eds.), Implicit memory: Theoretical issues (pp. 47-65). Hillsdale, NJ: Erlbaum.

SchwartZ, B. L., Rosse, R. B., \& Deutsch, S. I. (1993). Limits of the processing view in accounting for dissociations among memory measures in a clinical population. Memory \& Cognition, 21, 63-72.

Seamon, J., Marsh, R., \& Brody, N. (1984). Critical importance of exposure duration for attentive discrimination of stimuli that are not recognized. Journal of Experimental Psychology: Learning, Memory, \& Cognition, 10, 465-469.

Shimamura, A. P. (1986). Priming effects in amnesia: Evidence for a dissociable memory function. Quarterly Journal of Experimental Psychology, 38A, 619-644.

Shimamura, A. P. (1993). Neuropsychological analysis of implicit memory: History, methodology and theoretical interpretations. In P. Graf \& M. E. J. Masson (Eds.), Implicit memory: New directions in cognition, development, and neuropsychology (pp. 265-285). Hillsdale, NJ: Erlbaum.

Smith, M. E., \& Oscar-Berman, M. (1990). Repetition priming of words and pseudowords in divided attention and in amnesia. Journal of Experimental Psychology: Learning, Memory, \& Cognition, 16, $1033-1042$

Weldon, M. S., Roediger, H. L., III, Beitel, D. A., \& Johnston, T. R. (1995). Perceptual and conceptual processes in implicit and explicit tests with picture fragment and word fragment cues. Journal of Memory \& Language, 34, 268-285.

Wood, N. L., Stadler, M. A., \& Cowan, N. (1995, November). Memory without attention in Eich's (1984) procedure? Not so fast! Paper presented at the annual meeting of the Psychonomic Society, Los Angeles.

\section{NOTES}

1. It is important to distinguish between automatic encoding processes and automatic retrieval processes. Some researchers have proposed that automaticity during retrieval, as well as encoding, is central to performance on implicit memory tests (e.g., Jacoby, 1991; Jacoby et al., 1989). In the present study, we focus on the role of automatic encoding processes.

2. Isingrini et al. (1995) also examined the effects of age. The results discussed here specifically refer to the youngest of Isingrini et al.'s four age groups (age range 20 to 35 years), although the pattern of results did not differ across age groups. The youngest group bears the closest similarity to the subjects who participated in the Mulligan and Hartman (1996) study.

3. The Fisher-Hayter test is used for post hoc mean comparisons because (1) unlike the Newman-Keuls test, it controls the familywise Type I error rate at the nominal $\alpha$ level (.05 for this and subsequent tests); and (2) it is more powerful than the Tukey HSD test (see Kirk, 1995, pp. 148-150)

4. Base-rate guessing in the category-cued recall test may be measured with the number of intrusions in each load condition. Note that this contrasts with the measurement of priming in the category-exemplar production task and with the measurement of category-cued recall (Figure 1), both of which are based on proportions. The mean number of intrusions in the category-cued recall test $(.54, .54, .42$, and .67 for the 0 $1-, 3-$, and 5-load conditions, respectively) did not significantly vary over attentional loads $(F<1)$. An alternative measure of accuracy in recall tasks is the difference between the number of old words recalled and the number of intrusions. Analyses of the alternative measure produced the same results as those reported above.

(Manuscript received December 21, 1995; revision accepted for publication February 29, 1996.) 